\title{
Einführung der Analysenliste per 1. Juli 2009 - wie weiter?
}

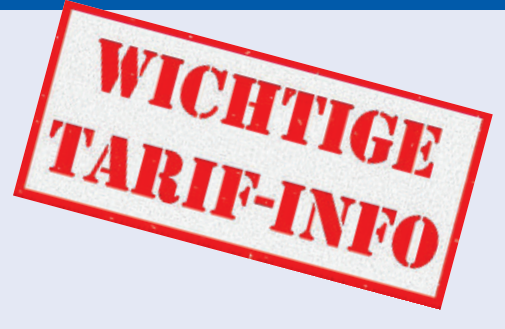

Per 1. Juli 2009 führt das Bundesamt für Gesundheit (BAG) - aller Kritik zum Trotz die neue, revidierte Analysenliste (AL) ein. Dabei wurde der von der FMH entwickelte Point-of-Care-Tarif [1] leider nicht berücksichtigt. Peter Indra, Vizedirektor des BAG, behauptet, dass dieser Tarif den Forderungen des KVG widerspreche. Dies obwohl der FMH ein gegenteiliges Rechtsgutachten von Herrn Eugster vorliegt.

Ernst Gähler ${ }^{a}$, Roman Fried ${ }^{b}$, Anton Prantl

a Dr. med.,Vizepräsident FMH

b Verein für med. Qualitätskontrolle

c Direktionspräsident Ärztekasse
In diesem Zusammenhang haben wir überprüft, ob das BAG den neu entwickelten Tarif wie angekündigt sachgerecht, transparent und betriebswirtschaftlich auf Basis eines mittleren Auftragslabors gerechnet hat." Nach zweimaliger Dateneinsicht beim BAG und dem Studium der wenigen Daten, die zur Verfügung standen, ergibt sich ein ernüchterndes Bild:

- Bei der neuen Analysenliste handelt es nicht um einen einheitlichen Tarif, sondern um ein kompliziertes Konstrukt aus neun verschiedenen Berechnungswegen.
Das neueste Gerät in den Berechnungsgrundlagen ist bereits 7 Jahre alt.

- Fehlermeldungen werden nicht seriös bearbeitet, sondern mit fachlich unqualifizierten Briefen abgewimmelt.

Unsere intensiven Bemühungen auf technischer und politischer Ebene sowie die «Kampfmassnahmen» haben es uns erlaubt, wichtige Allianzen zu knüpfen, die weiterhin Bestand haben. Die FMH hat ihre politischen Forderungen für die Ärzteschaft wiederholt

\section{Die Analysenliste ist nur mit grossem Aufwand aktualisierbar.}

Alle Tarife, welche auf fixen Eingabewerten basieren, werden beispielsweise bei Lohnanpassungen nicht automatisch aktualisiert

- $70 \%$ der Tarife der Grundversorgungsanalysen wurden nicht mit dem eigentlichen Tarif-Modell berechnet. Bei diesen Tarifen sind fixe Eingabewerte hinterlegt, welche die Firma PrimeNetworks auf nicht nachvollziehbare Weise festgelegt hat.

- Die Analysenliste ist nur mit grossem Aufwand aktualisierbar. Alle Tarife, welche auf fixen Eingabewerten basieren, werden beispielsweise bei Lohnanpassungen nicht automatisch aktualisiert. Das sind in der Grundversorgung 70\%, in der gesamten Analysenliste 50\% der Tarife.

1 Prantl A. Der Point-of-

\footnotetext{
* Die neu revidierte Analysenliste lässt sich auf der Website des BAG einsehen: www.bag.admin.ch $\rightarrow$ The-

men $\rightarrow$ Krankenversicherung.
} Care-Tarif: eine Übersicht. Schweiz Ärztezeitung 2009;90(7):238
- Die angekündigten Anpassungen an den technologischen Fortschritt haben nicht stattgefunden. für die Qualitätssicherung massiv gekürzt. Im alten spiel wird bei den Chemie-Analysen wie AST der Betrag für Kontrollen und Ringversuche von bisher Fr. 1.60 auf Fr. 0.08 gesenkt. prominent deponieren können. Doch leider konnten wir damit die Einführung der Analysenliste nicht verhindern. Nur Bundesrat Pascal Couchepin kann seinen eigenen Entscheid zurücknehmen. Er zeigt sich aber stur und sieht keinen Grund, etwas daran zu ändern. Verlierer sind die Patientinnen und die Hausärzte.

\section{Wie verhalte ich mich?}

Unsere juristischen Abklärungen haben ergeben, dass sowohl das weitere Abrechnen mit der bisherigen Analysenliste als auch eine Rechnungsstellung mit dem Point-of-Care-Tarif nicht zulässig und sogar strafbar sind. Peter Indra, Vizedirektor des BAG, hat an einer Medienkonferenz Anfang März 2009 eine Anleitung für die Anwendung der Analysenliste gegeben:

Der Taxpunktwert beträgt ab 1. Juli 2009 Fr. 1.-, dazu kommt bei der Präsenztaxe ein Zuschlagswert von Fr. 1.-, der bis am 31. Dezember 2011 gilt. Laut Peter Indra sollen sich drei Analysen pro Sitzung kosten- 
deckend abrechnen lassen, die restlichen Analysen seien halt an ein Auftragslabor zu senden.

\section{Handlungsanleitung}

Alle Analysenpositionen erhalten eine neue Positionsnummer. Zudem werden neue Positionen eingeführt. Die im Rahmen der Grundversorgung durchgeführten Analysen sind unterteilt in Analysen der Grundversorgung im engeren Sinn (Teilliste 1 und Teilliste 2), und in die erweiterte Liste für Fachärztinnen oder Fachärzte, welche zusätzlich zu den Analysen der Grundversorgung im engeren Sinn weitere Analysen durchführen dürfen.

\section{Die revidierte Analysenliste wird am 1. Juli 2009 eingeführt, obwohl noch gravierende Mängel vorliegen}

Grundlegend neu ist der Aufbau der Verrechnung von Analyse-Leistungen - neben der eigentlichen Leistung fallen eine ganze Reihe von Zuschlägen an:

- eine Präsenztaxe pro Tag und Patient;

- ein Übergangszuschlag pro Leistung;

- $\quad$ ein Zuschlag pro Leistung nach Typ der Analyse.

\section{Beispiele}

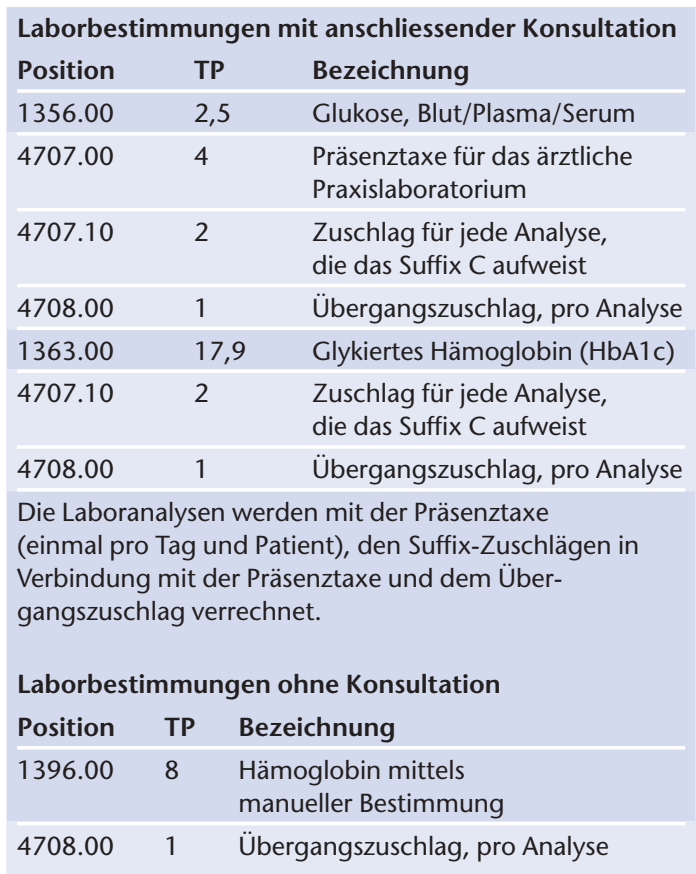

Zwei Konsultationen am gleichen Tag mit Laborbestimmungen

1. Konsultation

\begin{tabular}{|c|c|c|}
\hline Position & TP & Bezeichnung \\
\hline 1372.00 & 10 & Hämatogramm III \\
\hline 4707.00 & 4 & $\begin{array}{l}\text { Präsenztaxe für das ärztliche } \\
\text { Praxislaboratorium }\end{array}$ \\
\hline 4707.20 & 1 & $\begin{array}{l}\text { Zuschlag für jede Analyse, } \\
\text { die kein Suffix C aufweist }\end{array}$ \\
\hline 4708.00 & 1 & Übergangszuschlag, pro Analyse \\
\hline 1245.00 & 10 & C-reaktives Protein (CRP), qn \\
\hline 4707.10 & 2 & $\begin{array}{l}\text { Zuschlag für jede Analyse, } \\
\text { die das Suffix } C \text { aufweist }\end{array}$ \\
\hline 4708.00 & 1 & Übergangszuschlag, pro Analyse \\
\hline \multicolumn{3}{|c|}{ 2. Konsultation } \\
\hline 1372.00 & 10 & Hämatogramm III \\
\hline 4708.00 & 1 & Übergangszuschlag, pro Analyse \\
\hline 1245.00 & 10 & C-reaktives Protein (CRP), qn \\
\hline 4708.00 & 1 & Übergangszuschlag, pro Analyse \\
\hline
\end{tabular}

Die Präsenztaxe darf nur einmal pro Tag und Patient verrechnet werden. Deshalb darf bei der zweiten Konsultation keine Präsenztaxe für die Laboranalysen fakturiert werden. Da sich die Suffix-Zuschläge nur in Verbindung mit der Präsenztaxe verrechnen lassen, fallen auch diese bei der zweiten Konsultation weg.

\section{Zusammengefasst}

- Der Übergangszuschlag kann bis am 31. Dezember 2011 bei jeder Analyse verrechnet werden.

- Die Präsenztaxe darf einmal pro Patient und Tag verrechnet werden - unter der Voraussetzung, dass Laboranalysen im Praxislabor durchgeführt werden und eine Konsultation stattfindet.

- Die drei Zuschlagspositionen 4707.00/4707.10 /4707.20 dürfen zusammen pro Auftrag 24 Taxpunkte nicht überschreiten.

\section{Fazit}

- Die revidierte Analysenliste wird am 1. Juli 2009 eingeführt, obwohl noch gravierende Mängel vorliegen.

- Sie steht im Widerspruch zu den Forderungen des KVG (wirkmässig, zweckmässig, wirtschaftlich, sachgerecht). Die offensichtlichen Ungerechtigkeiten sind nicht akzeptabel und lassen sich nicht durch kurzfristige Korrekturen korrigieren. 